\title{
Research-led placements in Politics: A new approach?
}

Philippa Sherrington ${ }^{a}$, Barrie Axford ${ }^{b}$, Alasdair Blair ${ }^{c}$, Steven Curtis ${ }^{d}$, Richard Huggins ${ }^{b}$ and Caroline Marsh ${ }^{\mathrm{a}}$

${ }^{a}$ Department of Politics and International Studies, University of Warwick, Coventry. CV4 7AL. UK. Corresponding author: p.sherrington@warwick.ac.uk

${ }^{b}$ Department of Politics and International Relations, Oxford Brookes University.

${ }^{c}$ Department of International Studies and Social Science, Coventry University.

${ }^{d}$ Department of Law, Governance and International Relations, London Metropolitan University. 


\title{
Research-led placements in Politics: A new approach?
}

\begin{abstract}
The 'scholarship of engagement', derived from work undertaken by the Boyer Commission in the US, emphasises the possibilities of enhanced undergraduate learning through research, yet in the UK, this idea is less developed. Moreover, although the study of Politics and International Relations lends itself well to the use of placements to develop this model of learning, there are few examples of this in the UK. This article presents findings from a major research project The Scholarship of Engagement for Politics, examining the ways in which placement learning can affect the student experience.
\end{abstract}

Keywords: placements, research-led learning, scholarship of engagement for Politics

Running title: Research-led placements in Politics: A new approach? 


\section{Introduction}

Recent discussions on the development of learning and teaching within UK higher education recognise the importance of undergraduate research as an integral part of the curriculum, although the implementation of such remains in its infancy. The Scholarship of Engagement for Politics project contributes to this debate by linking undergraduate research to placement learning, and providing alternative menus for how this can be achieved. This project is developing the scholarship of engagement as a formal dimension of the Politics/International Relations curriculum, creating a repertoire of examples of the scholarship of engagement for Politics, and evaluating the impact and effectiveness of these placements upon student learning. The project does not seek to prove that placement learning enhances the student experience, but offers examples of the ways in which placement learning can affect the student experience, accounting for the differing institutional contexts and student diversity within the UK's academic community. The project has worked with students, placement providers, and academics to move away from the notion of placements as purely 'work' experience by establishing research-led placements, whereby students undertake a specified research task with the placement provider. This paper provides some critical insights into how this 'shift' in the perception of placement learning can affect the student experience. Students are encouraged to consider how abstract concepts or political ideas manifest themselves whilst on their placement, and then are asked to analyse their findings through the summative assessment for their placement learning. By experiencing 'politics in action', we observe how this embeds the placement learning experience into students' wider undergraduate studies in Politics and International Relations.

\section{Research-led learning through placements}

Our interest in developing the Scholarship of Engagement for Politics project derives, in part at least, from the significant contribution made by Ernest Boyer $(1990,1996)$. In a report for the Carnegie Foundation, Boyer argued for a much broader understanding of academic scholarship that reflected more accurately the actual range of staff activity, beyond a simple dichotomy between research and teaching, by placing significant emphasis on the wider importance and 
potential of scholarly activity. In addition, Boyer argued that American universities had moved away from their traditional commitment to public service and the civic agenda, and he stressed the need for a clear re-commitment to (public) service (learning) that might by best termed the 'scholarship of engagement' (Boyer, 1990, 1996).

Boyer outlines a model of scholarship that stresses four key areas of activity for university staff (Boyer, 1990). The first, the scholarship of discovery, consists of what can be understood as standard academic research. The second, the scholarship of integration, refers to the location of such research within wider contexts. The scholarship of sharing knowledge highlights the shared and communal nature of academic work and recognises more diverse audiences for scholarship than members of the academic community. Finally, Boyer identifies the application of knowledge, as a reflective practice and in which theory and practice meet, as a fourth key theme

The scholarship of engagement as Boyer understood it is rooted in a peculiarly American idea of higher education, with its commitment to service and the historic role of building and replenishing of the nation (Barber, 1998). Zlotkowski subsequently employed the term in relation to student service-learning experiences (2005: ix). More recently, it has been used to encapsulate all relations between institutions of higher education and their civic environs, including student internships and service-learning programmes (Percy et al, 2006). Boyer's work has been very influential in the US. The Carnegie Foundation has continued to fund major projects building on his work (Boyer Commission, 1999), through a variety of models and projects. For example, the Reinvention Centre, Sony Brook, New York University, Imagining America: Artist's and Scholars in Public Life or the Arts of Citizenship Program at the University of Michigan provide various examples of the critical engagement with 'the scholarship of engagement' within and across various institutions. ${ }^{1}$ Such developments pose interesting questions concerning the role and scope of university education and learning, and reflect considerable scholarly concerns with the scope of active learning, citizenship, student and university community engagement, as well as 
the application of knowledge and skills outside the classroom (Brew, 1999, 2003, Harkavy, I, 2006, Janesen, et al 2006).

In a UK context, where notions of the university and student service to the community are largely absent, it makes sense to redeploy this term in the sense of student engagement with the subject matter of degree courses. ${ }^{2}$ Besides providing the title of our project, Boyer's main contribution is the pedagogy underpinning our approach to placement learning. The report by the commission bearing his name and dedicated to his memory, 'Reinventing Undergraduate Education', sets out a programme for injecting a significant element of research into the undergraduate experience at America's research universities. '[C]arefully constructed internships' are cited as a key instrument in facilitating research-based learning on undergraduate programmes, as 'the experience can provide learning that cannot be replicated in the classroom' (Boyer Commission, 1999: 18-19). Similarly, from a British perspective, Zamorski highlights the importance of forms of fieldwork, including work placements, as a means of enhancing the research-led dimension of undergraduate degree programmes (Zamorski, 2000: 13). Our project is therefore informed not just by the research and literature on service learning and work-based learning, but also by a more general, and increasing concern in the UK with introducing research-based learning into the undergraduate experience (Blackmore and Cousin, 2003, Jenkins et al, 2003). This has been reflected by the growing interest amongst external stakeholders, for example the Higher Education Council and Research Councils and the increased interest among staff and higher education professionals in the enhancement of the student experience, independent learning and the link between staff research and learning and teaching (Jenkins and Healey, 2005). Perhaps most notably, it has been put into practice through the development of the Reinvention Centre for Undergraduate Research at the Universities of Warwick and Oxford Brookes, one of the UK Government funded Centres for Excellence in Teaching and Learning.

In such approaches to undergraduate activity, the possibility and merit of undergraduate research is valued as providing students with the opportunity to develop and enhance higher-level 
academic and transferable skills. This may include, the experience of 'real' research work and how a research project is carried out and how a research team works, the development of student research skills in areas such as project planning, data collection and analysis, the use of specialised equipment, and writing up findings. Transferable skills may well include group working, time and resource management, communication skills and the ability to reflect on their own learning and achievements. In these ways, projects such as ours not only work to extend academic and pedagogic opportunities for learning and development but broader issues of employability and the wider student experience. For our project, whilst we recognise and provide pre-placement support for students in developing their key skills, we have sought to downplay the development of these skills in this project. We wanted students not to see the placement experience as purely a work experience that would enhance their CV, but to appreciate the 'research' element of the placement. As shown below, the acquisition of key skills remains a motivating factor for students in opting to undertake a placement, but it is not the only factor.

\section{Placement Learning in Politics/International Relations.}

With research-led learning and teaching driving our inquiry, the project also evolved out of a sense that within the discipline of Politics//International Relations, placements could be a valuable and exciting new framework with which to develop research-led learning. Although we thought that the discipline lends itself well to the integration of placement opportunities, we found little evidence of such practice. Of the ninety-six UK and Irish Higher Education Institutions identified in our survey in which Politics/International Relations is taught at undergraduate level, sixty-five do not offer any kind of placement learning. Of the remaining thirty-one institutions, fourteen are pre-1992 universities or their Irish equivalent. The preponderance of 'new' universities is perhaps not surprising, given their history of innovation in teaching and learning methods and their received image as offering more 'applied' or vocation-oriented degrees than older institutions. At the same time, nineteen pre-1992 universities do not offer placement learning in Politics and International Relations, although the majority of abstainers (forty-six) come from the pre-1992 
sector. Our survey revealed much variation in practice. Some institutions offer one-year sandwich programmes, others concentrated placements - but all except one were over ten weeks in duration. Only eight of the thirty-one placement schemes identified run in the second year of the undergraduate curriculum. Some placements are available to all students, but most select, with take-up being on a voluntary basis. Occasionally there is a special placement module, but often the work is managed and assessed out of an existing module, and is focused upon skills rather than the discipline.

Such imbalances might well be explained in part by the different pedagogic traditions and institutional ethos of old and new universities, and, on the face of it, this might go some way to explain why comparatively well-resourced departments in the old sector either shy away from ,or else have not considered placement learning schemes. However, that would leave as unexplained its adoption by the fourteen 'older' institutions. In some of these, at least, the existence of placement 'champions' no doubt contributes to their vitality and it may well be the case that the role of such champions is paramount in initiating and sustaining any placement scheme. The interesting speculation is whether such schemes will wither and die when the champion moves on or retires.

It is also appropriate to speculate whether the absence of placement learning in many of the departments canvassed is a product of ignorance of the possibilities, concern about the resource implications, or a reluctance to countenance experience-related learning as relevant to the study of Politics and International Relations, even where it involves undergraduate research. Chief among such concerns are the difficulties of evaluating the impact and effectiveness of placements on student learning. Reluctance on the ground is mirrored in the relative lack of encouragement from professional sources. Certainly, the 2007 subject benchmark statements make no mention of placement learning, even though some aspects of prescribed transferable skills might benefit from the experience. Curiously, the QAA Code of Practice on Work-Based and Placement Learning (2007, Section 9) opines that 'students, particularly in current or recent 
employment, can bring a range of experience and knowledge to their studies', implicitly questioning the wisdom that sees little intellectual value in having students so engaged.

\section{Putting Politics into action}

Embedding placement learning in the Politics curriculum is not an easy task, and the practicalities can seem quite daunting for academics and students alike. To this extent, we have advocated that placements should be of short duration (between one and eight weeks), should run during the academic year alongside a student's programme of study, and should be regional wherever possible (to defray financial costs). The placement should be linked to a specific module, and should be structured by the learning outcomes of that module. The placement should also be formally assessed. From the inception of this project, and clarified by the survey results into the extent of placement learning in the UK, we argued that placement learning in the final year of undergraduate studies may not be as effective as earlier in their studies. Not only are students gearing up for their end of degree assessments, but the final year may be too late for students to reflect upon their placement learning experience within their wider and further academic studies. To this extent, this project focused upon the second year of the undergraduate curriculum as offering the best opportunity for students to connect their placement learning with their academic work. One of the key aims of our research is to identify whether these connections are possible, and if so, what sort of intellectual links students make between their placement learning and their academic studies in Politics and International Relations.

We set up a variety of placement opportunities with MPs, MEPs, regional government offices, local government, and non-governmental organisations. At the start of the project, we wanted to secure a wide-range of placements with non-governmental organisations, but found that these organisations were more reluctant to get involved than what we have termed the 'traditional' type of placements. MPs and MEPs are used to employing interns, and therefore have structures in place, whereas some non-governmental organisations can be small, and simply do not have the 
resources (staff or time) to provide placement opportunities. During these placements, students undertook a range of activities, ranging from drafting Parliamentary questions, researching and writing a speech on HIV and AIDS, working on a scrutiny survey for a local council, writing a brief on the current issues and events in Sri Lanka, researching into a Government White Paper, and designing questionnaires. We agreed with all placement providers that students should be exposed to specific research-based tasks, but of course, general office duties might feature as well. All students appreciated the benefits of having research-based tasks, for example:

'The work has been very interesting, and I'm incredibly grateful that my placement have given me a project where I'm not just making tea and doing the photocopying - the review that I am currently undertaking gives me a lot of freedom for personal thinking and reflection, rather than just working through a checklist of things to do.'

'Obviously it's the first speech I have ever had to write so [my provider] has edited a few things but the initial gist is all me!'

'The next week was spent designing a questions and the outline of a user consultation day that is coming up ... they wanted questions that would provide qualitative and quantitative data for a report that will be sent to local government on users' experience of local drug-treatment services and their experiences with pharmacies, drug-workers etc. I spent quite a long time dusting off forgotten research skills and trying to remember how Excel works!'

Most of the providers had some previous experience of recruiting interns, or providing work experience for school and university students. The majority of providers felt that by requiring the student to undertake a specified research-based task during the placement had significant benefits for the placement experience. From the provider's perspective, this approach forced to 
student to focus more intently on the general role and functions of that particular office, and better appreciate the context in which the research-based task was being executed.

We have worked with twenty-eight students at the three Universities involved in the project (Warwick, Coventry and Oxford Brookes) in three phases over the past two academic years. The integration of the placement into the curriculum has varied according to the institutional structure, thus providing us with a range of contexts to inform our research. At Coventry University, two modules were used: one on the politics of European integration, the other on UK politics. At the University of Warwick, placements also were offered via a second year module in UK Politics. At Oxford Brookes University, placement learning opportunities are delivered through a freestanding module called the Independent Study Module (ISM). With departmental approval, each student can elect to take one ISM from each of her/his fields during Stage 2 (years 2 and 3) of study, working to an agreed programme of research and assessment schedule. ISMs are designed to promote independent learning and involve a variety of innovative teaching and assessment techniques. Although the academic argument for our structure of the placements being embedded in the modules was to underpin the learning process, it was not always the case that the content of the module directly linked to the placement activity. The best example here is the fact that some students taking the UK Politics module at Coventry University went on placement to local government offices. However, while the module itself did not have a specific local government focus, students were able to draw parallels from the placement into the wider learning of the module, such as the extent to which governance within the UK is divided into different layers and the inter-relationships between these tiers. 'I am beginning to see issues work their way through the policy process .... I think a really good way to get an idea of the workings of the organisation would be to follow an issue around the committees like this -1 am beginning to get an idea of how they all relate to each other'

In terms of the actual mechanics, students registered for the modules outlined above at Coventry and Warwick Universities were chosen for placement on a competitive basis, and at Oxford 
Brookes by opting for an ISM with placement. The factors that influenced the decision as to which students were chosen were not just based on degree performance to date. Rather, students were asked to write a short piece of work as to how they thought the placement would benefit their studies. In this sense, we were seeking to identify the motivations of students, and how students felt a placement might benefit their academic studies. At the same time there were, of course, additional practical factors, such as the extent to which the placement on offer could dovetail with a student's curriculum. As the placement ran alongside the existing modules of study, it was important to ensure that the placement activity did not overly disrupt the degree as a whole. Nevertheless, it was the case that some placements did have a disruption factor, with some students going on placements that lasted for up to two or three weeks in a whole bloc, or finding it quite hard to manage their time in the sense of being on placement two days a week and in lecture rooms on the other days. However, in post-placement interviews, all the students recognised the benefit of the practical integration of the placement into their timetable. As one student reflected, 'this placement really did fulfil what I expected it to be, and, although the extra workload and cost has been a struggle for me, I wouldn't swap this first hand experience for anything'.

The number of student applications depended upon the institutional context and the regulations governing student choice of modules. For example, at Oxford Brookes, over the three rounds of placements, the number of applications from the potential pool of students averaged at four percent, whereas at Warwick University it was twenty-five percent. To this extent, there is an element of self-section. However, given the nature of our research, we do not see this as negative. We do not advocate compulsion. Placement learning carries certain risks and is not for every student. It may well be that only the more motivated students apply, and an argument can be made that weaker (in terms of less motivated) students may benefit more from the placement experience, both academically and at a personal level. Given the relatively under-developed nature of research-led placements within a UK context, our project took the view from the outset that we would not push the more reluctant students to apply for a placement opportunity. From a 
practical perspective, students who do not engage whilst on a placement may leave the placement provider feeling rather dissatisfied and not prepared to accept students in the future. Of the twenty-eight students who undertook a placement as part of our project, there has only been one failure, and this was due to the provider not providing a clear research task as previously agreed. We built into the module regulations a safety net so that if a student asks to terminate the placement for justifiable reasons, then the student simply reverts to the nonplacement assessment route within that module. We found that by asking students to keep a daily blog whilst on placement (which was a requirement but not formally assessed), we were able to monitor the placement in a non-obtrusive manner, and ensure that the student and provider were adhering to the pre-placement contract.

In terms of the formal learning process, our research is based on the premise that to embed placement learning into the curriculum, there should be a formal mode of assessment, which is subject, rather than skills specific. At Coventry, this accounted for fifteen percent of the final module mark, and at Warwick twenty percent. At Oxford Brookes, the formative assessment constituted the entire final mark for the ISM. We designed two different types of assessment: a reflective learning essay where students were asked to write about what they learned from the placement experience and how it contributed to their studies; and a specific content essay that drew upon the placement activities and related these back to a key concept, theory, or theme within the particular module. Of these two approaches, it was noticeable that the students who had to write a reflective learning diary were less engaged in viewing the placement as a research project and viewed it in a more holistic sense. By contrast, students following the content specific route were from the outset focused on the task of using the placement as a research project to underpin the learning on the module. As part of our own research, we also conducted interviews with the students, and it was very clear that the type of assessment regime informed their own reflections about the placement experience:

I began to collate and bring together lots of information with which I felt I was making lots of progress. I spoke to everyone - in corridors, meetings, on the phone and in the office, 
investigating the Forums and it felt like I was piecing together an investigation. In fact, it was fascinating seeing all the differing views and agendas regarding the forums and could certainly be described as "politics in action!"'

As discussed above, we have sought not to over-emphasise the potential development of key skills when undertaking a placement. However, all the students who undertook a placement included the development of these skills when asked, prior to the placement, to list what their expectations were. Moreover, many of the students recognised that their key skills improved because of their placement learning. As one student stated, 'my people, ICT, French speaking, travel and research skills have all been lifted'.

As well as interviewing students immediately after their placement experience, we have been able to investigate the extent to which a placement has an impact upon the students' wider academic studies in the medium-term. Although the project is ongoing, and further investigations will be carried out later this year, the six-month follow-up questionnaire given to students who undertook a placement in the first round has provided some interesting interim findings. Twothirds of those students stated that the placement not only gave them a better appreciation of the discipline, but also had a real connection to their academic studies. Half of the students have been able to deploy the placement experience in subsequent class discussions in different modules, and half felt that their study of key concepts and theories in Politics/International Relations had been awakened by their placement experiences. Finally, eighty percent of respondents agreed that their academic experience had been enriched by placement learning. However, we have also found that some students who undertook a placement with a less obviously political organisaton, and primarily with the non-governmental organisations, found it harder to make the link with their wider academic studies than those students who undertook placements within the tiers of UK government. To some extent, this may because these students are not necessarily studying the role of non-governmental organisations in great depth within their academic programmes, or it may be due to the type of research they undertook as part of their 
placement not enabling them to make the links sufficiently. Not all students found the link difficult, for example, one student stated: 'I had never really thought about policies arising in this way so it was very surprising to me and learnt a lot about NGOs and their importance and over the years what they had achieved from the suffragettes to the WTO'. It is interesting for us, though, to see how students' perceptions of politics are reflected back into their placement experience, and their views on the intellectual benefits of that experience.

\section{Conclusions}

The lesson from the experience of service learning in the US is that, while the effects of participating in such opportunities on students 'were often significant, they were not large' (Eyler and Giles, 1999). However, an earlier study, focusing on political science students, makes a stronger claim for significant impacts on learning (Markus, Howard and King, 1993). In the UK context, Lord Norton has demonstrated how one-year placement-learning opportunities in Westminster have improved degree results (Norton, 2004). However, due to the competition for places on the British Politics and Legislative Studies degree programme and the selection of single honours Politics students sent on one-semester placements, it may be that final degree results are as much a reflection of the rigorous selection process weeding out weaker students.

Our research to date demonstrates that by shifting the emphasis of placement learning from 'work experience' to 'research-led learning' in Politics/International Relations can have a real and tangible effect upon enhancing the student experience.

'Who'd have thought something that you learn in a class room would actually be relevant in real life! The main reason I undertook this placement was to see how much was relevant, and to see the actual, physical consequences of the theory that is learnt in lectures, so this was particularly useful as far as I was concerned.' 
Knight and Yorke argue that the complexity of higher education makes it impossible to guarantee a 'tight-coupling between teaching, resources, tasks, learning and judgements of achievement' (Knight and Yorke, 2004: 17-18). There will be slippages. Hence, instead of striving to ensure the objectives are met in each and every instance, the best we can do is to create opportunities (what they call 'affordances') for the sort of learning we intend. We do not argue that undertaking a placement enhances student learning in every case; only for setting up and structuring the placements so to offer the maximum affordances for students to make the most of the opportunities. Research-led placements in Politics/International Relations, if embedded within a module and degree programme, can have a positive effect upon a student's wider academic studies. Students are often encouraged, or perhaps forced to question what they have already studied during their placement, and some appreciate better the link between abstract theories and concepts and reality. It may be steep at times, but it appears to be a positive learning curve for those students. 


\section{Notes}

1 For details of these activities, see http://www.carnegiefoundation.org, http://ws.cc.stonybrook.edu/Reinventioncenter, http://www.ia.umich.edu, http://www.umich.edu/ mserve/artsofcitizenship respectively.

${ }^{2}$ For an attempt to inject a civic component into placement learning in Britain, see Annette 2005. 


\section{References}

Annette, J (2005) 'Character, Civic Renewal and Service Learning for Democratic Citizenship in Higher Education', British Journal of Educational Studies, 53 (3): 326-340.

Barber, B. (1998) 'A Passion for Democracy: American Essays, Princeton: Princeton University Press.

Blackmore, P and Cousin, G (2003) 'Linking Teaching and Research Through Research-Based Learning' in Educational Developments, 4 (4).

Boyer, E. (1990) Scholarship Reconsidered: Priorities of the Professoriate, New York: The Carnegie Foundation for the Advancement of Teaching, University of Princeton.

Boyer, E. (1996) 'The scholarship of engagement', Journal of Public Outreach 1 (1),11-20.

Boyer Commission (1999) Reinventing Undergraduate Education: A Blueprint for America's Research Universities, Stony Brook, NY, Carnegie Foundation for University Teaching.

Brew, A. (2003) 'Teaching and Research: New Relationships and their Implications for Inquirybased Teaching and Learning in Higher Education.' Higher Education Research and Development, 22 (1): 3-16.

Brew, A. (1999) 'Research and Teaching: Changing Relationships in a Changing Context.' Studies in Higher Education, 24 (3): 291-301.

Harkavy, I. (2006) 'The Role of Universities in Advancing Citizenship and Social Justice in the $21^{\text {st }}$ Century.' Education, Citizenship and Social Justice, 1 (1): 5-37.

Janesen, Th., Chioncel, N. and Dekkers, H. (2006) 'Social Cohesion and Integration: Learning Active Citizenship.' British Journal of Sociology of Education, 27 (2): 189-205.

Jenkins, A., Breen, R., Lindsay, R and Brew, A (2003) Reshaping Teaching in Higher Education: Linking Teaching with Research, London: Kogan Page.

Jenkins, A. and Healey, M. (2005) Institutional Strategies to Link Teaching and Research, York, Higher Education Academy.

Knight, P. and Yorke, M (2004) Learning and Employability in Higher Education, London: Routledge Falmer.

Markus, G., Howard, J. and King, D (1993) 'Integrating Community Service and Classroom Instruction Enhances Learning: Results from an Experiment', Education Evaluation and Policy Analysis, 15 (4): 410-419.

Norton, P. (2004) 'Experience-Based Learning in Parliament (Westminster): The Pilot Project' CSAP Final Report, www.c-sap.bham.ac.uk/resources/project_reports/admin/extras/17_P_04.pdf.

Percy, S., Zimpher, N. and Brukardt, M (eds.) (2006) Creating a New Kind of University: Institutionalizing Community-University Engagement, Bolton, MA: Anker Publishing.

Zamorski, B (2000) Research-Led Teaching and Learning in Higher Education, (Norwich: UEA, Centre for Applied Research in Education.

Zlotkowski, E (2005) 'Foreword' in Chapdelaine, A., Ruis, A., Warchal, J. and Wells, C ServiceLearning Code of Ethics, Bolton, MA: Anker Publishing. 


\section{About the authors}

The authors are all members of the team for The Scholarship of Engagement for Politics project. This project is funded by the Higher Education Funding Council for England (HEFCE) through its Fund for the Development of Teaching and Learning (FDTL), Project No: FDTL 16/03. For more details of the project, see www.politicsinaction.ac.uk.

Barrie Axford is Professor of Politics and Head of Department of Politics and International Relations at Oxford Brookes University.

Alasdair Blair is Professor of International Relations in the Department of International Studies and Social Science at Coventry University.

Steven Curtis is a Research Fellow on the Scholarship of Engagement for Politics project, and is Lecturer in International Relations in the Department of Law, Governance and International Relations, London Metropolitan University, formally at Coventry University.

Richard Huggins is the Assistant Dean of Academic Affairs at Oxford Brookes University where he teaches postgraduate courses on research methods and democracy.

Caroline Marsh is the FDTL Project Manager for The Scholarship of Engagement for Politics, and is based in the Department of Politics and International Studies at the University of Warwick.

Philippa Sherrington is the FDTL Project Director, and Associate Professor in EU Politics and Public Policy in the Department of Politics and International Studies at the University of Warwick. 